\title{
ANALYSIS OF SEISMIC EXPLORATION DATA USING THE RAY METHOD: KANEGAHARA FAULT STRUCTURE NEAR KYOTO, JAPAN
}

\author{
Yoshimasa KoBAyASHI and Masanori HoRIKE \\ Geophysical Institute, Faculty of Science, Kyoto University, \\ Kyoto, Japan \\ (Received October 23, 1986; Revised June 1, 1987)
}

\begin{abstract}
A seismic reflection exploration has been conducted at a site on the western margin of the Kyoto basin. An air gun suspended under water in a river was used as a source device, and a measuring line was spread over $800 \mathrm{~m}$ on an embankment of the river. An underground structure model has been determined by comparing the travel times and the amplitudes of main phases in the recorded seismograms with those computed by the ray method. A vertical step of subsurface bedrock is found below the middle of the measuring line due to the presence of a reverse fault with a vertical offset of about $200 \mathrm{~m}$. The inferred model is compatible with existing geological, seismological and gravitational data.
\end{abstract}

\section{Introduction}

The Kanegahara fault which is the object of the present study has been thought to extend through the confiuence point of three rivers, Katsura, Uji, and Kizu (Fig. 1). This area of confluence, which is structurally significant because three major rivers converge to it, was selected as a site of seismic surveys to investigate the subsurface structure of the Kanegahara fault. It is probable that the basin margin mountainous on both sides of the river confluence have been built up by recent tectonic movements in this area.

The location of our site is on the western margin of the Kyoto basin. The Nishiyama fault (No. 37 in Fig. 1) strikes NS and is situated $4 \mathrm{~km}$ to the west. The Kanegahara fault (No. 39) is one of many minor reverse faults (Katagihara fault (No. 36), Takahata fault (No. 38), etc.) that are associated with the Nishiyama fault which is a major N-S trending high angle reverse fault with the hanging wall to the west. The Kanegahara fault is thought to be one of many secondary reverse faults to the east of the Nishiyama fault. An earthquake of magnitude 4.7 occurred at $12.1 \mathrm{~km}$ depth approximately below the rivers' confluence point on the 5 th of May in 1984. This earthquake may indicate that the fault system (No. 36 through 39 ) in the west margin of the Kyoto basin is still active.

The mode of movement observed along the tectonic lines on both margins of 


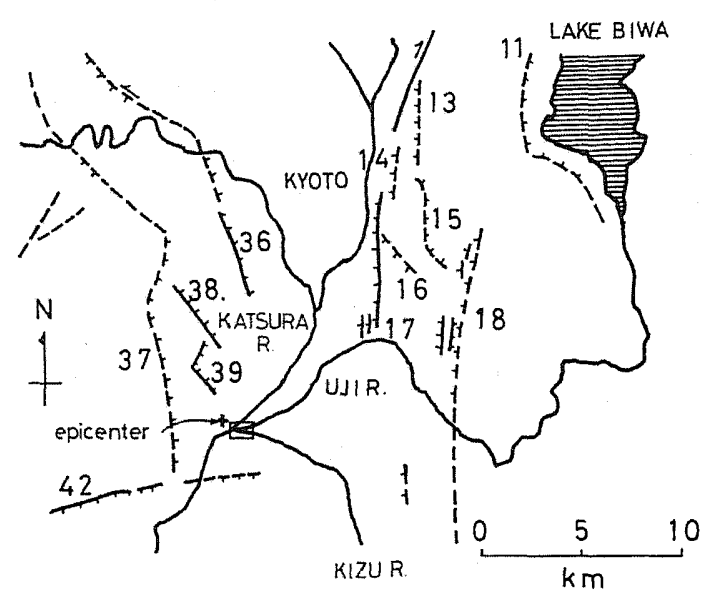

Fig. 1. Fault system around Kyoto after RESEARCH GrouP FOR ACTIVE FaUlTs (1980). 11, Hiei; 13, Shishigatani; 14, Kiyomizu-Nishi; 15, Yamashina-Nishi; 16, Inariyama; 17, Momoyama; 18, Oobaku; 36, Katagihara; 37, Nishiyama; 38, Takahata; 39, Kanegahara faults; and 42, Arima-Takatsuki tectonic line. A small rectangle at the confluence of three rivers indicates the site of the present study. +, Epicenter of the May 5, 1984 event.

the Kyoto basin (e.g., Nos. 38 and 39 for the west margin and No. 18 for the east margin) is either thrusting of Paleozoic bedrock over the Pliocene to Pleistocene Osaka group or flexure of the Osaka group accompanying thrust movement of the Paleozoic bedrock. Steeply dipping strata of the Osaka group have been observed along the Katagihara, Takahata, and Kanegahara faults. According to MizuYama (1953) the relative displacement due to this movement decreases gradually from north to south and seems to disappear somewhere near the confluence point. In contrast to this UEJI (1961) describes a fault to the south bank of the rivers that may be an extension of the Kanegahara fault. Furthermore, gravity data available (MURAKAMI et al., 1975) suggest a vertical step of the subsurface bedrock amounting to $400 \mathrm{~m}$ at the confluence. Therefore, a question arises as to whether the fault extends to the south beyond the confluence point or not.

To answer this question we made a series of micro-tremor measurements and seismic reflection explorations on an embankment between the Uji and Kizu rivers at the same site as that in the present study in 1984 (IMAZUMI and KoBAYASHI, 1985). The subsurface structure inferred through the investigations is summarized as follows: an abrupt change in micro-tremor amplitudes across the site suggests a vertical step of the subsurface bedrock at about 400 to $600 \mathrm{~m}$ west of the Goko bridge (Fig. 2). A reflector which presumably corresponds to the upper surface of the bedrock was detected at about $100 \mathrm{~m}$ depth only on the western side (mountain side) of the vertical offset by the reflection explorations using the Common-Depth Point (C.D.P.) method. No corresponding reflector could be detected at this level on 
the basin side. Bedrock was not detected here because of insufficient energy generated by our source, weight dropping. However, the depth of the bedrock on the basin side is estimated to be about $500 \mathrm{~m}$ based on the predominant period of $0.5 \mathrm{~Hz}$ as detected from micro-tremor measurements.

In view of the present knowledge of the Kanegahara fault it is interesting to investigate a more detailed structure of the fault. In 1985 we conducted a seismic reflection exploration at the same site as in 1984, using an air gun as a much stronger shot device.

The present paper describes the data acquisition in this exploration and presents the records obtained. Next, an analysis based on the ray method used for interpreting the records is summarized. Then a subsurface structure model is determined by comparing the records with computed travel times as well as synthetic seismograms, both by the ray method. Lastly, the validity of the structure determined by the present study is discussed by referring to existing geological, seismological and gravitational data.

\section{Field Experiment and Records}

\subsection{Data acquisition}

A measuring line (approximately EW) was spread along an embankment between the Uji and Kizu rivers at an angle to the postulated fault. The line extended from the Goko bridge over $800 \mathrm{~m}$ to the west. Geophones of $28 \mathrm{~Hz}$ frequency were planted at every $10 \mathrm{~m}$. Two shot points were located near the bottom of the Uji river, 1 to $2 \mathrm{~m}$ below the water surface, at approximately 0 and $800 \mathrm{~m}$ from the Goko bridge (Fig. 2). We used an air gun (Bolt PAR Air Gun, Model $600 \mathrm{~B}, 40 \mathrm{cu}$. inch or $151 \mathrm{~cm}^{3}$ ) as a source device with pressures between 90 and $110 \mathrm{~atm}(9$ and $11 \mathrm{MPa}$ ). A digital data-acquisition system developed by TsuTsur $e t$ al. (1986) with the aid of a personal computer was used. By using this system we performed vertical stacking in the field as many times as necessary by observing the quality of the traces on CRT. Stacking was performed 5 to 30 times depending on the $\mathrm{S} / \mathrm{N}$ ratio of every trace. Data were sampled at every $1 \mathrm{~ms}$.

\subsection{Records}

The eastern edge of the bedrock on the hanging wall of the fault (determined in a previous study (IMAZUMI and KOBAYASHI, 1985) to be $430 \mathrm{~m}$ west of the Goko bridge) is defined in this study at $500 \mathrm{~m}$ (distance is measured from west to east throughout the present paper). Figures 3(a) and 4(b) show seismograms for shots at $100 \mathrm{~m}$ and $800 \mathrm{~m}$, shots $\mathrm{W}$ and $\mathrm{E}$ (indicated at $70 \mathrm{~m}$ and $870 \mathrm{~m}$ respectively by arrows in time sections, because the shot points were not in the line of geophones as shown in Fig. 2).

In reflection seismic records employing a single source, it is normally difficult to discriminate direct waves or primary reflected waves from the many complex arrivals at the surface. Complex arrival features may be caused by the following 


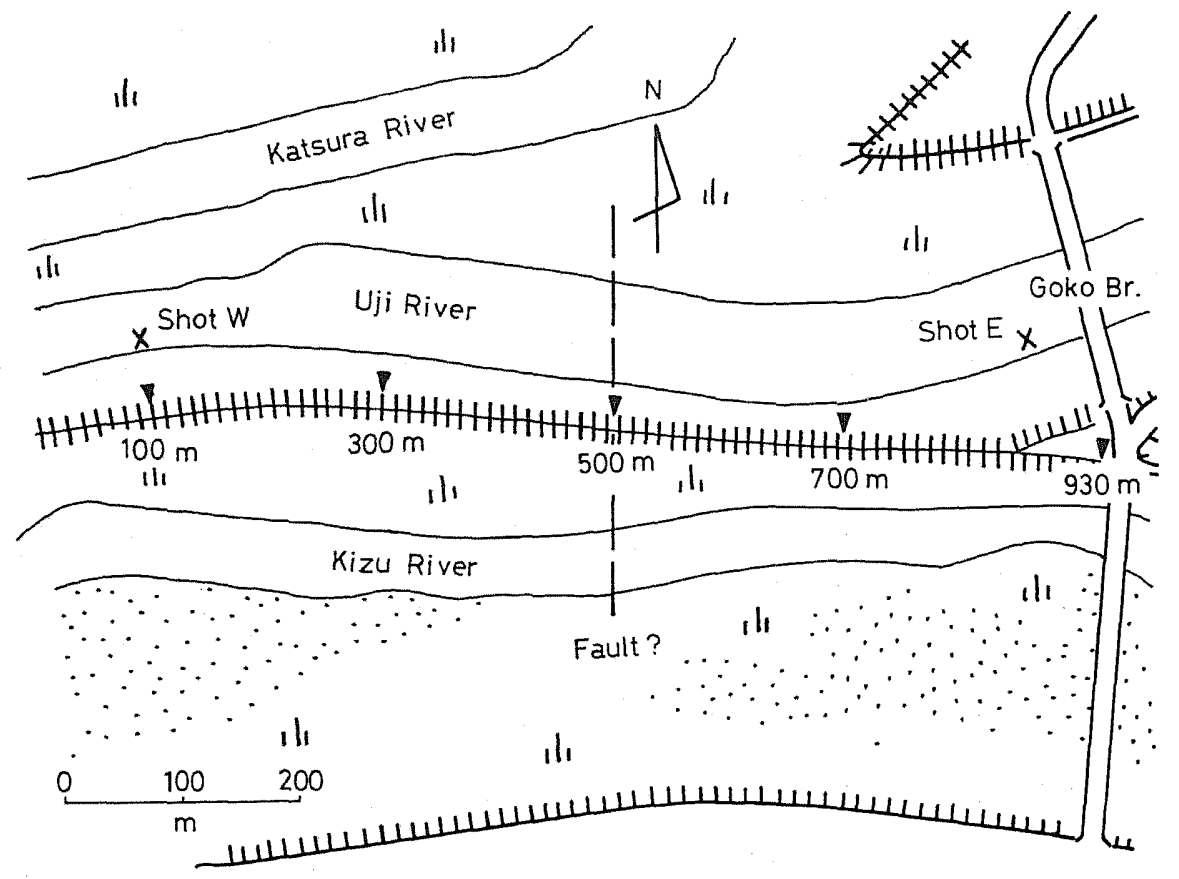

Fig. 2. Map of the site studied. A measuring line over $800 \mathrm{~m}$ was spread on the embankment between the Uji and Kizu rivers straddling a postulated fault (broken line). Air gun was shot at two points underwater in the Uji river (shots $E$ and $W)$.

three effects: first, the signature generated at the source (air gun) is not an impulse but a vibration with certain duration; second, there are not only direct and primary reflected $\mathrm{P}$ waves but also reflected SV waves as well as their multiples; third, there are diffracted waves caused by minor inhomogeneities in each layer. In a standard process of refiection seismology, as has been developed in the petroleum industry, deconvolution is applied to improve the resolution of primary waves by suppressing multiples. We will follow a similar procedure for these records. The results of prediction-error filtering with a filter length $50 \mathrm{~ms}$, and a prediction distance $10 \mathrm{~ms}$ (PEACOCK and TREITEL, 1969) are shown in Figs. 3(b) and 4(b).

Figure 3(a) gives a times section for shot $\mathrm{W}$, where every trace is normalized by its maximum amplitude. In the deconvolved traces in Fig. 3(b) we can identify 4 phases, $A, B, C$, and $D$. It is readily seen that the phases $C$ and $D$ are parallel. $D$ is either a multiple reflection of primary wave, $\mathrm{C}$, or a following peak of a multiplepeaked wavelet with $\mathrm{C}$ as its first peak. If the former is the case, the amplitudes of $\mathrm{C}$ should be larger than those of D. Since this is not the case, it is probable that they belong to a single wavelet of non-minimum phase. Apparent velocities for the phases $\mathrm{A}, \mathrm{B}$, and $\mathrm{C}$ are of increasing order, and therefore they are likely 


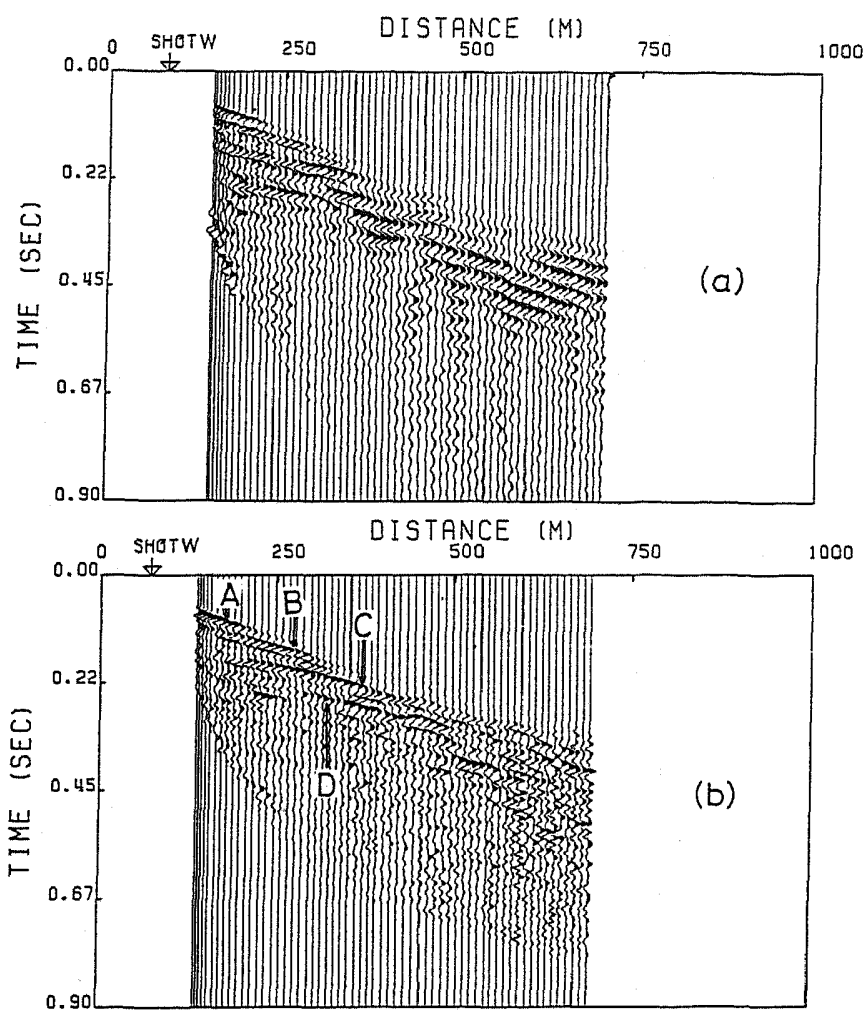

Fig. 3. Time sections for shot W. (a) Unfiltered: every trace is normalized by its maximum amplitude. (b) Same as (a) after application of prediction-error filtering (filter length, $50 \mathrm{~ms}$; and prediction distance, $10 \mathrm{~ms}$ ).

independent, i.e., a direct wave and primary reflected waves from various interfaces.

Figure 4 shows the time sections for shot E. As in Fig. 3(a), Fig. 4(a) shows the normalized traces and Fig. 4(b) the deconvolved traces. Figure 4(b) shows that the phases are clearer in the deconvolved traces. We can identify 6 phases-A, B, C, D, $\mathrm{E}$, and $\mathrm{F}$. In this case again, $\mathrm{C}$ is evidently parallel to the forerunning phase $\mathrm{B}$, which is not shaded. Because both disappear at about $400 \mathrm{~m}$ and because the amplitudes of $\mathrm{B}$ are smaller than those of $\mathrm{C}$, they also may belong to a single nonminimum phase wavelet. Features of the phases may be summarized as follows:

1) Phases B and C disappear at about $400 \mathrm{~m}$;

2) Phase $D$ appears at about $450 \mathrm{~m}$;

3) Phase E appears at about $350 \mathrm{~m}$; and

4) Phase $F$ appears at about $450 \mathrm{~m}$ and disappears at about $350 \mathrm{~m}$.

Phase E seems either to disappear at about $200 \mathrm{~m}$ or to cross with phase $\mathrm{D}$, and the decision as to which actually occurs is hard to determine based only on this 

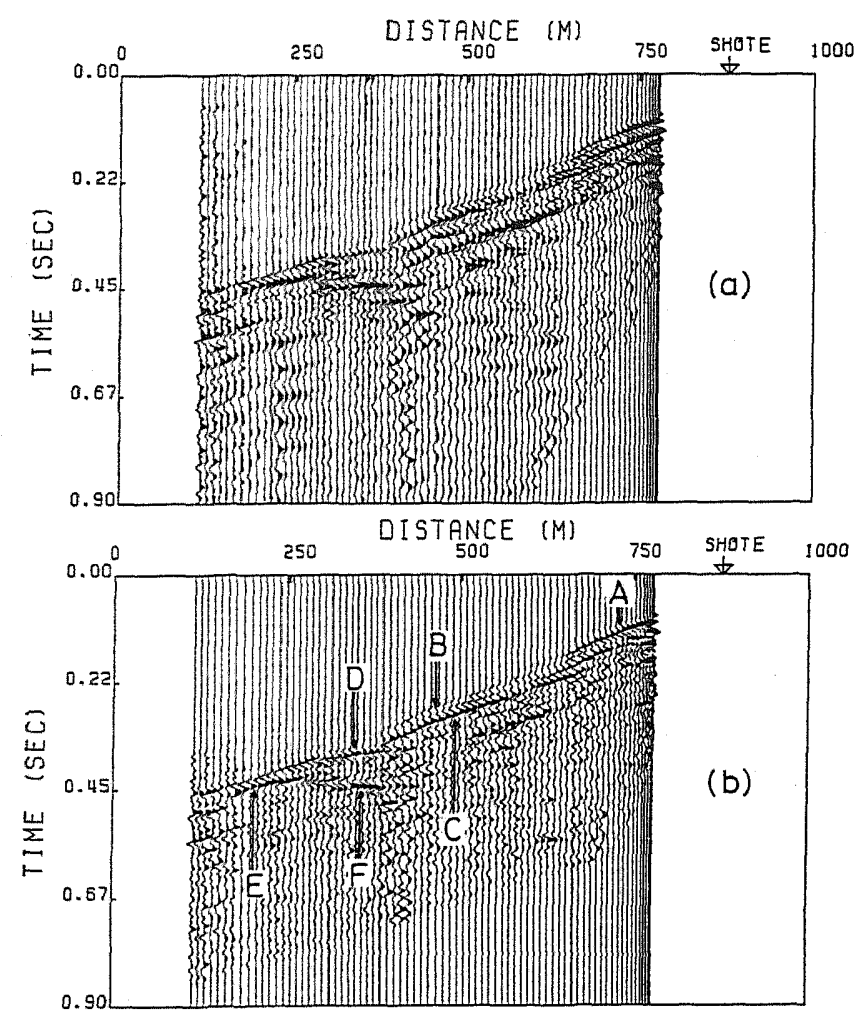

Fig. 4. Time sections for shot E. (a) and (b) are similar to those in Fig. 3.

record. We will now try to construct a subsurface-structure model which accounts for the phase features listed above.

\section{Analysis Procedure}

3.1 A procedure for determining subsurface-structure model

We have determined the 2-dimensional subsurface structure by the following procedure: Starting from a model,

1) we revise the model to fit the travel times by ray tracing with those observed from a shallow level to successively deeper levels;

2) we calculate synthetic seismograms from a P-wave point source for the 2dimensional model obtained in the stage 1) by the method of ČERVENÝ et al. (1977), and compare the synthetic with the observed seismograms to determine how to modify the model given by 1 );

3) we repeat processes 1) and 2) until we get travel times and a distribution of amplitudes which agree reasonably well with those observed.

It should be noted, however, for the synthesis we have made use of a sourcetime function slightly different from that by ČERVENÝ et al. (1977); more specifically, 
we have given a real source-time function $R(t)$ as

$$
R(t)=B(t) * \delta(t)
$$

where $B(t)$ is a physically realizable band-pass filter with a flat pass band between 20 and $80 \mathrm{~Hz}, \delta(t)$ is the delta function, and $*$ denotes convolution. Then, we have made a complex source-time function by

$$
S(t)=R(t)+i H(R(t))
$$

where $H$ is the Hilbert transform. By using $S(t)$ as a source-time function, a sharper onset may be obtained and we can use also information of compression or tension of the onsets.

\subsection{Determination of the subsurface-structure model}

We have repeated the process given in 3.1 for every record. First we have determined the structure up to the bottom of the fourth layer (interface between 2,120 and $3,000 \mathrm{~m} / \mathrm{s}$ layers, Fig. 6) in the western half of the site mainly from the records of shot $\mathrm{W}$. Then we have determined the structure in the eastern half of the site as well as that of the fault from the records of shot $E$ without changing the structure in the western half.

In this process we have tried to maintain interfaces as horizontal as possible while permitting the variation of velocity in every layer exclusively in the vertical direction except for the 3rd layer. The possibility of an eastward-dipping normal fault has been eliminated, because the presence of such a structure would result in no reflected ray from the bedrock from shot $\mathrm{E}$ in the western half of the measuring line (see Fig. 5).

Figure 6 gives a model inferred from both records for shots $\mathrm{E}$ and $\mathrm{W}$ in the present study. A detailed process for constructing this model will be given in the next section. The numerical values in the illustration are $P$-wave velocities in $\mathrm{m} / \mathrm{s}$. The velocities within a layer vary linearly between the indicated values. The first two layers of $2 \mathrm{~m}$ and $10 \mathrm{~m}$ in thickness respectively and their velocities are not specifically shown in the profile. The velocities of these layers are $1,650 \mathrm{~m} / \mathrm{s}$ and $1,000 \mathrm{~m} / \mathrm{s}$, respectively. The third layer contains horizontal velocity variations while the others are only vertically variable. In the next section we will examine how well this model can explain the records from both shots.

\section{Comparison of Observed and Synthesized Records}

\subsection{Shot $W$}

Figure 7(a) illustrates ray tracing. Figure 7(b) shows travel times with observed seismograms. The phases A, B, and C (see also Fig. 3) are well reproduced by the model. The low-velocity second layer and the horizontally variable third layer are introduced mainly for explaining phase A. The horizontal variation in velocity in the third layer is designed to eliminate the effect of the lateral offset of the shot 


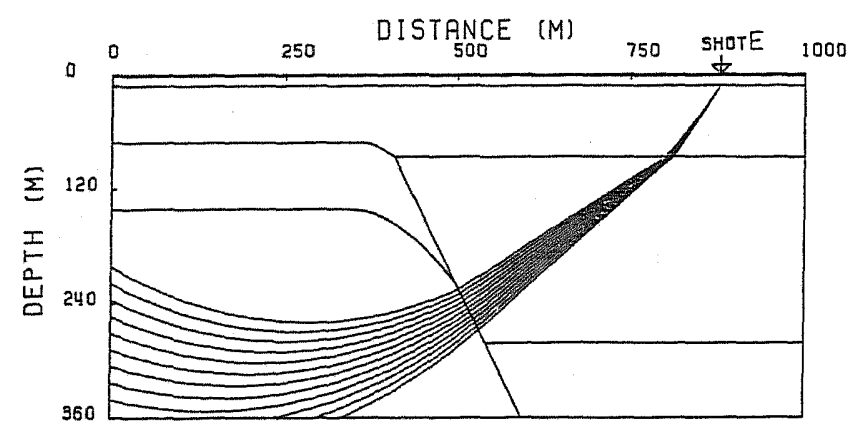

Fig. 5. Ray tracing for a model with a normal fault. Possibility of normal fault is eliminated, since in this case no reflection from the bedrock on the eastern side can reach the surface on the western half of the measuring line, which is inconsistent with observation.

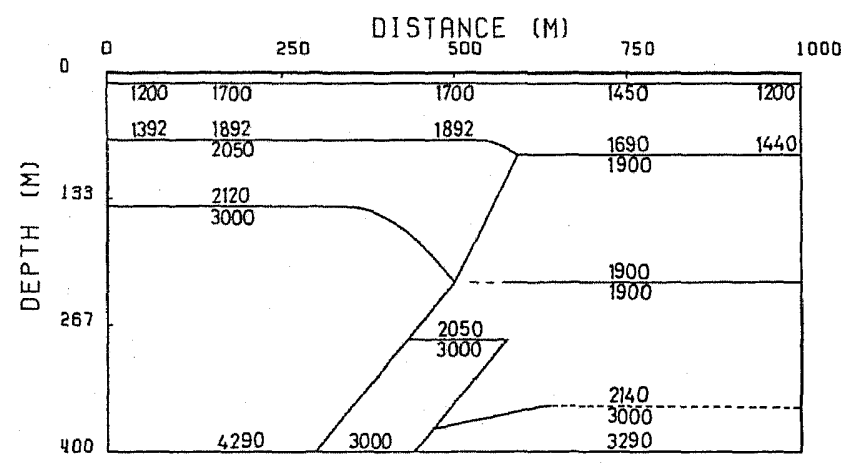

Fig. 6. Subsurface-structure model inferred in the present study. Numerical values are $\mathrm{P}$-wave velocities in $\mathrm{m} / \mathrm{s}$. The velocities within a layer vary linearly between the indicated values.

points from the measuring line shown in Fig. 2. For receivers nearer to the shot points a larger percentage of travel distance is located within the river bed, where the velocity should be lower than that along the embankment. This situation can be modeled in the 2-dimensional profile by lower velocities in the nearest portions of the third layer to the shot point.

Figure 8 gives a comparison of observed and synthesized seismograms for shot W. In the observed seismograms (Fig. 8(a)) relative amplitudes among traces are retained. In the synthetic seismograms (Fig. 8(b)) the spatial variation of amplitudes of reflected phases, $\mathrm{C}$, agrees relatively well with the observed one; however, in the synthesis, phase $C$ reaches slightly farther to the east than in the observation. The synthetic seismograms reproduce the phases A and B well at nearer distances; however, they do not agree well with the observed seismograms at distances farther to the east than about $250 \mathrm{~m}$. This lack of agreement may have been caused by the 


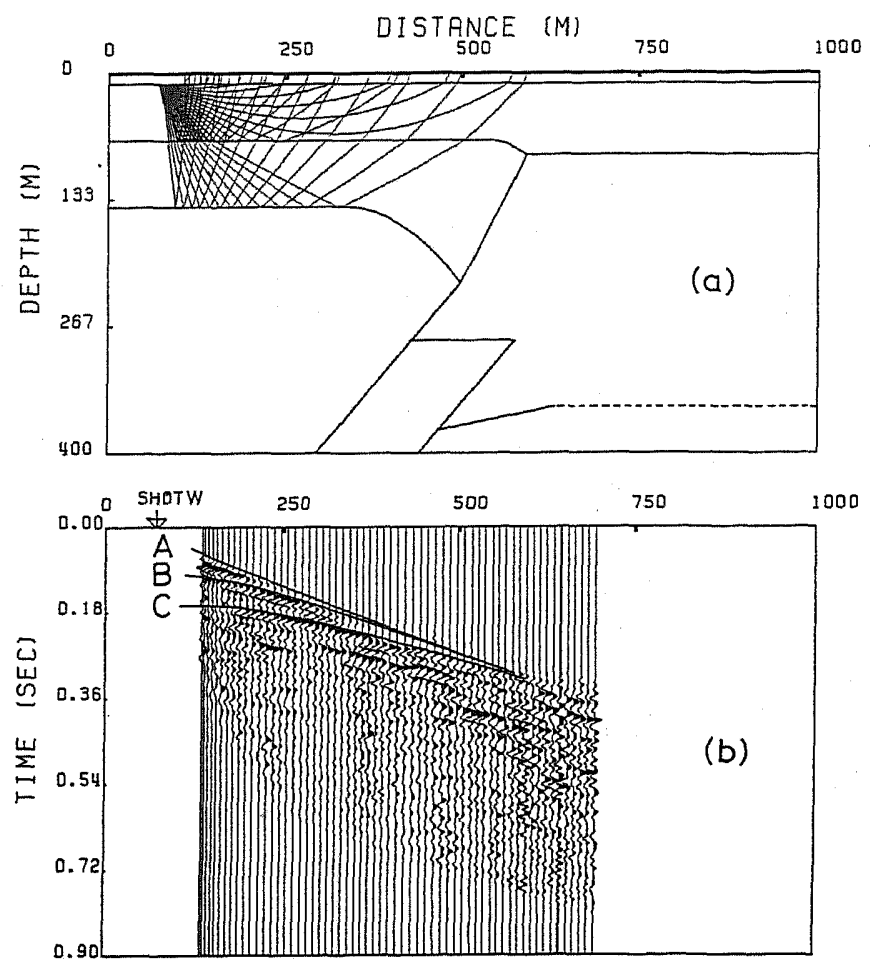

Fig. 7. Ray tracing (a), and travel times with observed seismograms (b) for shot W.

ignorance of presumably very low $Q$ values in the upper three layers of the site. The main portions of the rays corresponding to the phases $\mathrm{A}$ and $\mathrm{B}$ are situated in these layers while large portions of the rays corresponding to phase $C$ are in the fourth layer (see Fig. 7). An alternate but less likeily reason may be that there was a computational error due to the zeroth-order approximation of the ray theory and an unsatisfactory evaluation of geometrical-spreading effect at nearly critical incidences (ČERVENÝ, 1983).

\subsection{Shot $E$}

We show the rays from shot $\mathrm{E}$ in two figures, Figs. 9 and 10, in order to avoid confusion caused by too many rays drawn in an illustration. In Fig. 9, travel times of phases $A$ to $F$ are well reproduced. In this case again, a lateral variation is introduced into the third layer for explaining phase A. This model also explains other features relatively well (Fig. 9(a)). First, phase B disappears at about $400 \mathrm{~m}$; second, phases $E$ and $F$ appear at about $350 \mathrm{~m}$ and $450 \mathrm{~m}$, respectively. Figure 10(a) illustrates the rays with different emergent angles from those in Fig. 9(a). In Figs. 9 and 10 it is apparent that the phase $\mathrm{F}$, a reflection from the deepest interface, does 

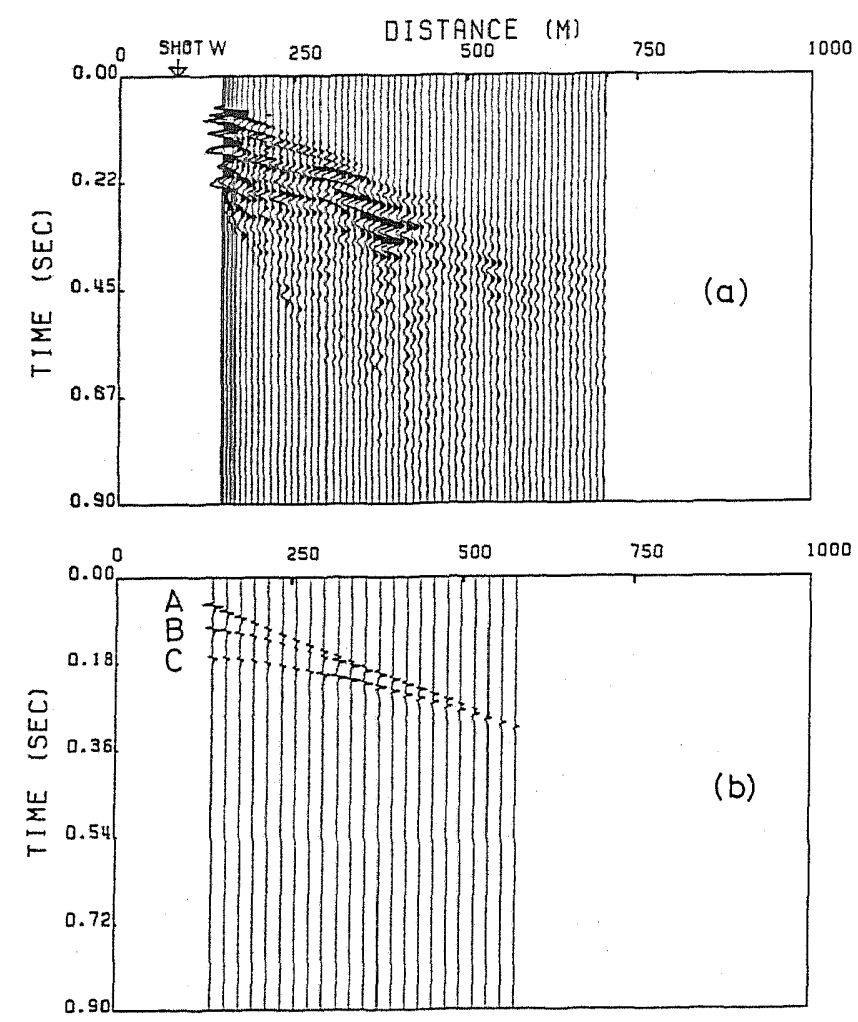

Fig. 8. Comparison of observed (a) and synthesized seismograms (b) for shot W. In (a), relative amplitudes among traces are retained.

not reach farther than about $350 \mathrm{~m}$. By ray tracing, phase $\mathrm{D}$ should appear at about $600 \mathrm{~m}$ while in the observation this phase first appears clearly at about $450 \mathrm{~m}$.

This apparent discrepancy may have been caused by either 1) an incorrect assumption regarding the shape of the phase- $\mathrm{D}$ reflector, or 2) that the reflected phase between 450 and $600 \mathrm{~m}$ is too small to be identified among larger phases. To examine the possibility of 1 ) we have varied the shape of the reflector, i.e., the dips of the reflector and the fault, to a resonable extent, but no essential improvement was obtained. The possibility of 2) cannot be eliminated completely, because this phase between 410 and $450 \mathrm{~m}$ could be made slightly clearer by deconvolution (compare (a) and (b) in Fig. 4) making it possible to improve resolution and trace the phase slightly farther to the east. Better designed filtering may result in still further improvement.

Figure 11 is a comparison of observed (a) and synthesized (b) seismograms for shot $\mathrm{E}$. Relative amplitudes are retained among traces in the observed seismograms. Also in this figure the synthesized phases, A and B, reach slightly farther west than those observed. This may also have been caused by the presence of low $Q$ values in 

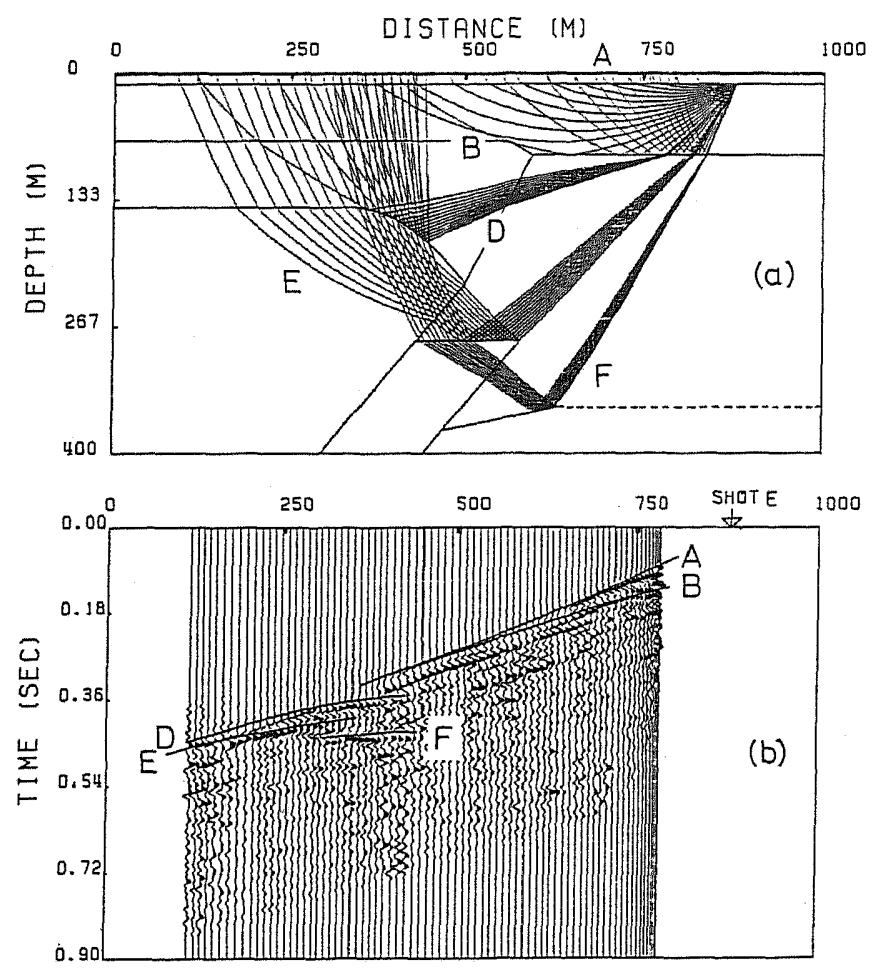

Fig. 9. Ray tracing (a) and travel times with observed seismograms (b) for shot E.

the upper three layers of the site. The phases D, E, and F are reproduced relatively well.

\section{Discussion}

The acquired model (Fig. 6) implies that the Kanegahara fault is a reverse fault. The possibility of a normal fault has been eliminated in an early stage of the present analyses as described in 3.2 (Fig. 5). The reverse fault model is reasonable in view of geological and seismological evidence available.

In the northern part of the Kanegahara fault some layers of the Osaka group were observed to be overthrust by Paleozoic strata (Nishiyama Research Group, 1967). More recently an outcrop of a reverse fault was observed at Chohoji-Hirao, Nagaoka city (Ishida, Personal Communication, 1985). This location corresponds to the southern end of the Takahata fault which is thought similar in character to the Kanegahara fault. The character of these faults is consistent with the regional stress field, EW compression, inferred from Quaternary tectonic movements (HuZiTA, 1980).

The hypocenter of the earthquake of May 5, 1984 was at $135^{\circ} 41^{\prime} 19.6^{\prime \prime} \mathrm{E}, 34^{\circ}$ 

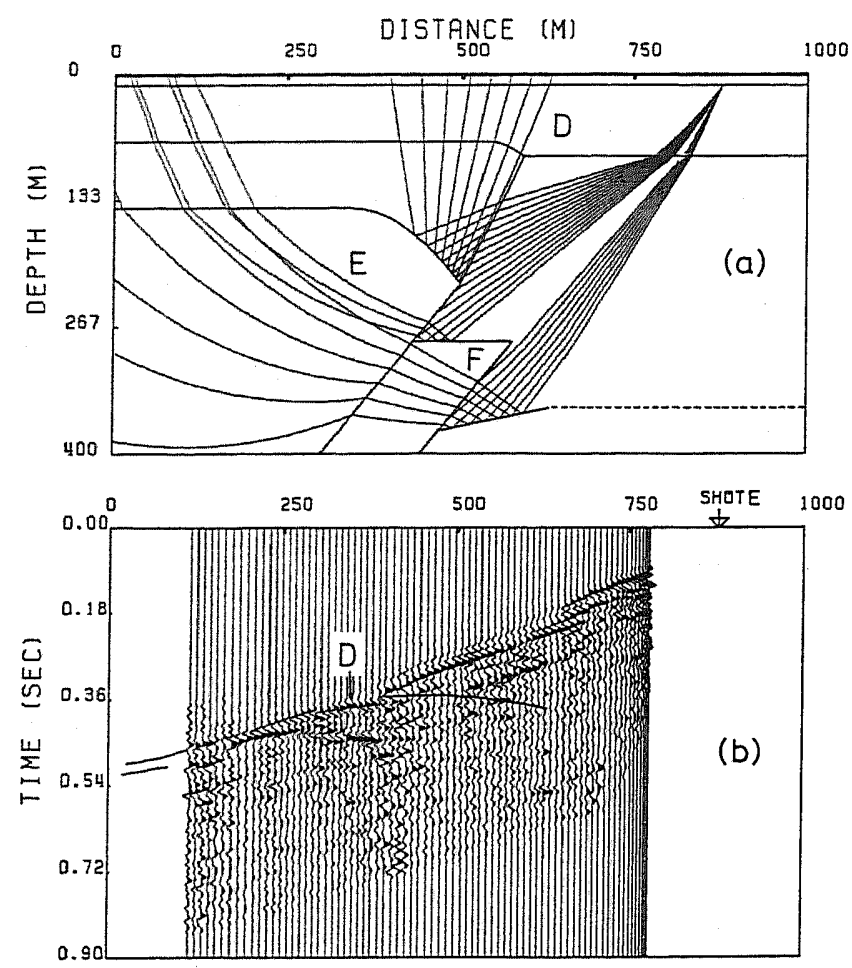

Fig. 10. The same as Fig. 9 except for emergent angles from the shot point.

$53^{\prime} 24.3^{\prime \prime} \mathrm{N}$ and $12.1 \mathrm{~km}$ in depth (KuroIso, 1984). The hypocenter is about $900 \mathrm{~m}$ west of the intersection of the Kanegahara fault and the measuring line. The faultplane solutions (nodal planes) were $\mathrm{N} 51^{\circ} \mathrm{W} / 30^{\circ} \mathrm{S}$ and $\mathrm{N} 25^{\circ} \mathrm{E} / 82^{\circ} \mathrm{S}$, and the former corresponds to slightly left-lateral reverse faulting while the latter corresponds to right-lateral strike-slip movement. The former plane is more consistent with the orientation of the inferred fault in the present study and suggests that the fault determined has been caused by a similar tectonic stress as that which generated this earthquake.

Concerning the depth of the bedrock, the results of our analysis may seem inconsistent with some of the existing information. For example, the depth has been estimated by the C.D.P. method as $100 \mathrm{~m}$ on the west side of the fault (IMAZUMI and KoBAYASH, 1985), while it has been shown to be $140 \mathrm{~m}$ in the present exploration. However, the depth of $100 \mathrm{~m}$ by the C.D.P. method was estimated from a two-way reflection time of $150 \mathrm{~ms}$ based on an assumption of an r.m.s. velocity of $1,400 \mathrm{~m} / \mathrm{s}$. If we calculate the two-way reflection time to the bedrock with our velocity model, it is also seen to be approximately $150 \mathrm{~ms}$. This shows that our phase $\mathrm{C}$ for shot $\mathrm{W}$ is identical to the clear reflection in the C.D.P. method. Thus, the estimate from our study is more reliable, since we have determined the depth based not only on the 

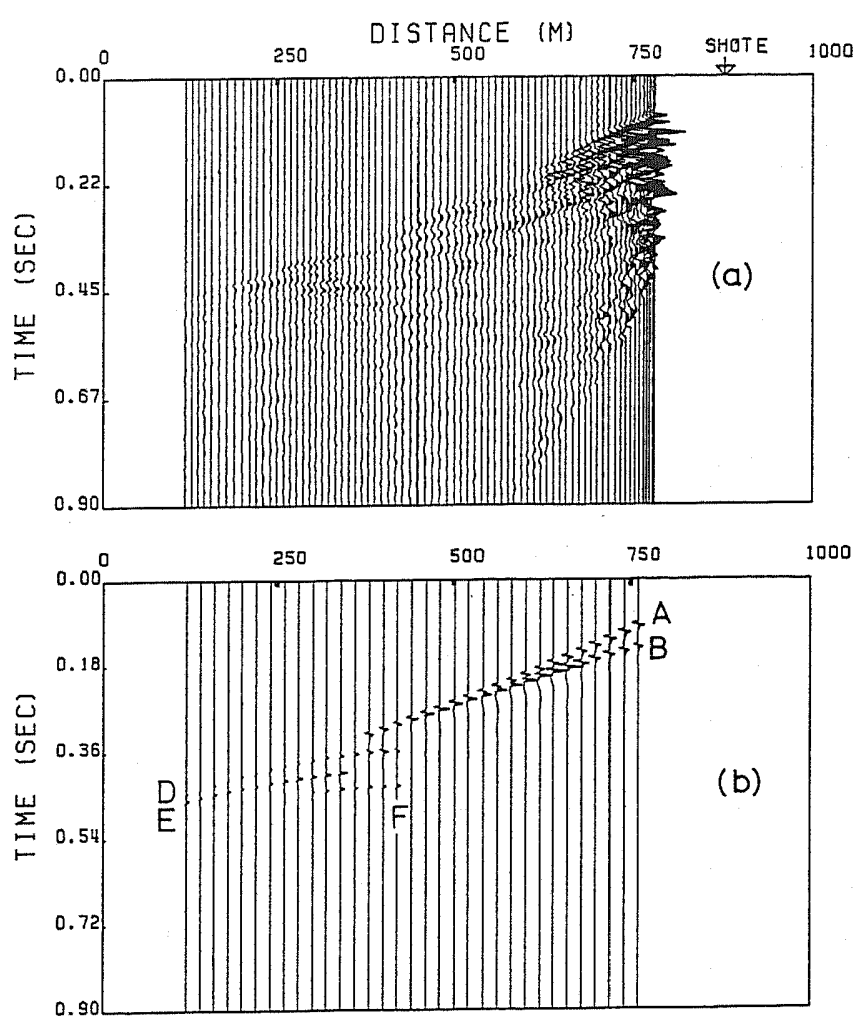

Fig. 11. Comparison of observed (a) and synthesized seismograms (b) for shot E. In (a), relative amplitudes among trace are retained.

r.m.s. velocity up to the $\mathrm{C}$ horizon but on interval velocities estimated from other reflected phases in the shallower subsurface.

Other information on the depth of the bedrock is obtained from a gravity survey conducted by MURAKAMI et al. (1975) at the same site. They have estimated the depth as $100 \mathrm{~m}$ on the west side and as $500 \mathrm{~m}$ on the east side of the fault, while our results give $140 \mathrm{~m}$ on the west side and $350 \mathrm{~m}$ for a limited part of the interface on the east side. The model for the gravity survey is two-layered, and the vertical offset can be reduced somewhat by increasing the density difference between unconsolidated deposit and bedrock, which was calibrated for the central part of the basin. However, the vertical offset of the bedrock across the fault amounting to $400 \mathrm{~m}$ in gravity survey is substantially larger than that amounting to $210 \mathrm{~m}$ in the present survey. This discrepancy may be primarily due to the different character of the survey methods. A gravity survey gives a macroscopic structure around the site while a seismic method yields a local one. The gravity survey may give an average value for the depth of bedrock while the seismic survey gives a precise depth specific only to the subsurface penetrated by the seismic rays. It is interesting in this 
connection to note that our result has given a deeper bedrock depth on the hangingwall side and a shallower one on the foot-wall side as compared with the result of the gravity survey. This may suggest a local drag effect on the strata by thrusting, west side upthrown. A similar mode of movement to the double thrust in our model also may explain the shallower depth to bedrock east of $500 \mathrm{~m}$ at out site.

As for the validity of our model, the present result (Fig. 6) has been attained after a number of trial-and-error repetitions, and there are few possible models that satisfy the observation equally well. Therefore, this model is, on the whole, satisfactory except for the very eastern tip of the bedrock on the hanging wall, for which we could not reproduce corresponding phases. An analysis of seismic data in a complex subsurface structure is generally difficult. However, if we have adequate a priori information, we can get reliable results by the ray method from relatively little data compared with those needed for the C.D.P. method.

We thank K. Irikura and E. L. Harp for critical reading of the manuscript and invaluable suggestions for improving it. We thank S. Abe, T. Kagawa, T. Tsutsui, T. Iwata, E. Fukuyama, T. Kuriyama, S. Kaneshima, M. Hoshiba, M. Fujita, and K. Yoshizaki for assistance in the field experiment. $C$. Igarashi has made an air gun available. A. Kuroiso provided us with parameters of the earthquake of May 5, 1984. The Ministry of Construction has permitted us to use its facilities for the experiment. All computations have been conducted on a FACOM M-382 at the Data Processing Center of Kyoto University. This research was supported in part by a project for Earthquake Prediction in the KinkiKeihanshin Area, Kyoto University. Criticisms by anonymous reviewers were helpful in improving the manuscript.

\section{REFERENCES}

ČER VENY, V., Synthetic body wave seismograms for laterally varying layered structures by the Gaussian beam method, Geophys. J. R. Astron. Soc., 73, 389-426, 1983.

Červený, V., I. A. MolotKov, and I. PŠEnČík, Ray Method in Seismology, Univerzita Karlova, Praha, 1977.

HuziTA, K., Role of the Median Tectonic Line in the Quaternary tectonics of the Japanese Islands, Mem. Geol. Soc. Jpn., 18, 129-153, 1980.

ImAZumi, T. and Y. KoBAYASHI, The Kanegahara tectonic line in the south-western part of the Kyoto basin as revealed by microtremor measurement and shallow reflection method, Geophys. Explor., 38, 155-162, 1985 (in Japanese with English abstract).

Kurorso, A., The earthquake at Oyamazaki, Kyoto Prefecture of May 5, 1984, Bull. Earthq. Predict. in the Kinki-Keihanshin Area, No. 3, 9-13, 1984 (in Japanese).

MrzuYama, T., Relation between faults and landforms along the western border of Kyoto basin, Geogr. Rev. Jpn., 26, 1-9, 1953 (in Japanese with English abstract).

Murakami, H., M. Satomura, F. Takeuchi, N. Goto, and K. Yoshikawa, Gravity exploration in the southern part of the Kyoto basin, Geophys. Explor., 28, 268-276, 1975 (in Japanese with English abstract).

NishiYama Research Group, The Osaka group in the south-western Piedmont region of Kyoto basin, Earth Sci., 21, 1-10, 1967 (in Japanese with English abstract). 
Peacock, K. L. and S. Treitel, Predictive deconvolution: Theory and practice, Geophysics, 34, 155-169, 1969.

Research Group for Active Faults, Active Faults in Japan, the University of Tokyo Press, Tokyo, 363 pp., 1980 (in Japanese).

Tsutsul, T., S. ABE, and Y. KOBAYASHI, Data acquisition system for seismic exploration using a personal computer system, Geophys. Explor., 39, 106-113, 1986 (in Japanese with English abstract).

UeJ, T., Geological Map of Kyoto Environs, Research Institute Mineral Resources, Kyoto, 1961 (in Japanese). 